\title{
X-ray Diffraction Patterns of Activated Carbons Prepared under Various Conditions
}

\author{
Badie S. Girgis ${ }^{1, \uparrow}$, Yassin M. Temerk ${ }^{2}$, Mostafa M. Gadelrab and Ibrahim D. Abdullah \\ ${ }^{1}$ National Research centre, 12622 Dokki, Cairo, Egypt \\ ${ }^{2}$ Faculty of Science, Assiut University, Assiut, Egypt \\ ${ }^{3}$ Sugar and Integrated Industries, Deshna, Qena, Egypt \\ ^e-mail: girgisbs@hotmail.com \\ (Received February 28, 2007; Accepted May 11, 2007)
}

\begin{abstract}
A series of activated carbons (ACs) were derived from sugarcane bagasse under two activation schemes: steam-pyrolysis at $600-800^{\circ} \mathrm{C}$ and chemical activation with $\mathrm{H}_{3} \mathrm{PO}_{4}$ at $500^{\circ} \mathrm{C}$. Some carbons were treated at $400,600^{\circ} \mathrm{C}$, or for $1-3 \mathrm{~h}$, and/or in flowing air during pyrolysis of acid-impregnated mass. XRD profiles displayed two broad diffuse bands centered around $2 \theta=23$ and $43^{\circ}$, currently associated with diffraction from the 002 and $100 / 101$ set of planes in graphite, respectively. These correspond to the interlayer spacing, Lc, and microcrystallite lateral dimensions, La, of the turbostratic (fully disordered) graphene layers. Steam pyrolysis-activated carbons exhibit only the two mentioned broad bands with enhancement in number of layers, with temperature, and small decrease in microcrystallite diameter, La. XRD patterns of $\mathrm{H}_{3} \mathrm{PO}_{4}$-ACs display more developed and separated peaks in the early region with maxima at $2 \theta=23,26$ and $29^{\circ}$, possibly ascribed to fragmented microcrystallites (or partially organized structures). Diffraction within the $2 \theta=43^{\circ}$ is still broad although depressed and diffuse, suggesting that the intragraphitic layers are less developed. Varying the conditions of chemical activation inflicts insignificant structural alterations. Circulating air during pyrolysis leads to enhancement of the basic graphitic structure with destruction and degradation in the lateral dimensions.
\end{abstract}

Keywords : Activated carbon, $\mathrm{H}_{3} \mathrm{PO}_{4}$-activation, steam pyrolysis, graphite structure, $\mathrm{X}$-ray diffraction

\section{Introduction}

Carbonaceous materials such as graphite, soot, chars, coke, and coals have characteristic structural properties which differ from mostly amorphous to completely graphitic crystalline structure. The degree of order of these structures clearly depends on the thermal treatment of the material as well as the type of precursor of the carbonaceous material. Currently used X-ray diffraction techniques for the measurement of graphene sheet size and turbostratic crystallite thickness were developed earlier by Warren [1,2], and by others [3-7]. In the most widely accepted model of the structure of "turbostratic" carbon, the atoms are arranged in layers but stacked randomly instead of the order ABABA-the sequence of graphite and interlayer spacing also occur randomly. It is generally accepted [8], that the development of turbostratic structures of carbon take place above $1200^{\circ} \mathrm{C}$. Information about these parameters is significant to comprehend the processes such as pyrolysis, gasification, graphitization, etc. Oberlin [9] demonstrated that the $700-1200^{\circ} \mathrm{C}$ range is the most significat for the production of activated carbons of large surface areas. In this stage, basic structural units are claimed to associate and the number of layers reaches 8-10 [10].
A knowledge of the structural ordering in activated carbons (ACs), as affected by the treatment conditions, is very important for following and / or understanding of the activation processes. Porous carbons are a non-graphite carbon characterized by internal surface areas ranging up to 3000 $\mathrm{m}^{2} \mathrm{~g}^{-1}$. X-ray analysis show that the structures of ACs is composed of carbon atoms in arrangements which approximate roughly to a short-range, layered (lamellar) structure. Some of these layers are stacked only approximately parallel to each other over distances up to a few nanometers. Consequently X-ray diffraction shows line broadening of only the principal graphite diffraction bands. This broadening is usually interpreted in terms of dimensions of a hypothetical crystallite. Although the crystallite concept has been used when comparing structures in carbons, it has to be stressed that the crystallite does not exist as such within these structures [11]. The building block in carbons is primarily graphite sheets, which are characterized by strong covalent bonding in the basal plane to three adjacent carbons and weak Van der Waals bonding between the basal planes [12]. However, the structure of AC is thought to be much less ordered than that of graphite [13]. Thus, in case of chars and ACs, the solid part of their structures is supposed to be composed of small aromatic layers with size about $1 \mathrm{~nm}$, 
and of disordered carbon [14]. The aromatic layers often pile up in 2-3 up to 8-10 to form stacks, and the disorganized carbon are present in aliphatic chain periphery of aromatic layers and cross-linkage structures [15], denoted by "turbostratic structure". In other words, aromatic layers and disorganized carbons form crystallite and non-crystallite components, respectively, to form microstructure in the solid part of activated carbons. Slit-shaped micropores in several ACs, has been suggested to exist between disk-like crystallites composed of stacking aromatic layers [16-18]. The crystallites are considered to be small, as mentioned above, that the microporosity of AC must be influenced strongly by its micro-structure, especially the status of stacking structure of aromatic layers [15].

Currently the X-ray diffraction (XRD) parameters which have been used to characterize the structure of ACs are the apparent crystallite dimensions Lc (height) and La (diameter). The apparent Lc and La obtained from the widths of (002) and $(100 / 101)$ profiles and $\mathrm{d}_{002}$, are the most frequently used parameters for describing structural ordering [15]. The peak centered around $25^{\circ}$, corresponding to the (002) set of planes, was used to measure the pseudographitic interlayer spacing, $\mathrm{d}_{002}$, and to calculate the average crystallite height, Lc, by means of the Debye-Scherrer formula. The latter formula was also used to calculate the average crystallite width, La, from the peak centered around $45^{\circ}$, which corresponds to the (100/101) set of planes [19]. Many research papers have been published on the graphitization study of various carbonaceous materials, using the XRD technique, supplemented by other methods [13-15, 20-24].

The present study reports the XRD patterns of a series of activated carbons derived from three bagasse fractions (whole, fiber and pith) and treated under various schemes of activation (chemical activation with $\mathrm{H}_{3} \mathrm{PO}_{4}$ or single-step steam pyro- lysis). It aims to demonstrate the development of structure of prepared ACs under action of varying preparation conditions (acid concentration and/or temperature of treatment, duration and flowing air). The XRD patterns are presented so to compare and contrast between their similarity or dissimilarity, in addition to the impact of carbon precursors.

\section{Materials and Methods}

\subsection{Materials}

Three sugarcane bagasse fractions were subjected to activation (whole bagasse: $\mathrm{B}$, bagasse fiber: $\mathrm{F}$ and bagasse pith: P). Three groups of activated carbons were investigated: ICarbons prepared under the steam-pyrolysis scheme $[25$, 26], II- Carbons obtained by chemical activation with $\mathrm{H}_{3} \mathrm{PO}_{4}$ $[27,28]$ under standard conditions, and III- Carbons derived by chemical activation with $\mathrm{H}_{3} \mathrm{PO}_{4}$ under modified variable conditions. Description of the conditions of preparation are given in Table 1.

\subsection{XRD patterns}

An X-ray diffractometer (PW-2103, Philips) was used to investigate the diffraction patterns of the activated carbons. The patterns were run with Ni-filtered copper radiation $(\lambda=$ $1.5405 \AA$ ) at $35 \mathrm{KV}$ and $20 \mathrm{~mA}$, and scanning speed of $2^{\circ}$ in $20 \mathrm{~min}^{-1}$. Diffraction profiles were recorded for all samples.

XRD patterns were analyzed for the structural parameters using the classical Debye-Scherer equations [10].

$$
\begin{aligned}
& \mathrm{Lc}=0.9 \lambda / \beta_{002} \cos \theta_{002} \\
& \mathrm{La}=1.94 \lambda / \beta_{100 / 101} \cos \theta_{100 / 101} \\
& \mathrm{n}=\mathrm{Lc} / \mathrm{d}_{002}
\end{aligned}
$$

\begin{tabular}{|c|c|c|c|}
\hline Notation & Conditions of preparation & Notation & Conditions of preparation \\
\hline BS 600 & Whole $\mathrm{B}, 2 \mathrm{~h}$, steam at $600^{\circ} \mathrm{C}$ & F 40 & B fiber, $40 \% \mathrm{H}_{3} \mathrm{PO}_{4}, 500^{\circ} \mathrm{C}, 3 \mathrm{~h}$ \\
\hline BS 700 & Whole $\mathrm{B}, 2 \mathrm{~h}$, steam at $700^{\circ} \mathrm{C}$ & F 50 & B fiber, $50 \% \mathrm{H}_{3} \mathrm{PO}_{4}, 500^{\circ} \mathrm{C}, 3 \mathrm{~h}$ \\
\hline \multirow[t]{2}{*}{ BS 800} & Whole $\mathrm{B}, 2 \mathrm{~h}$, steam at $800^{\circ} \mathrm{C}$ & & \\
\hline & & P 30 & B pith, $30 \% \mathrm{H}_{3} \mathrm{PO}_{4}, 500^{\circ} \mathrm{C}, 3 \mathrm{~h}$ \\
\hline FS 600 & $\mathrm{~B}$ fiber, $2 \mathrm{~h}$, steam at $600^{\circ} \mathrm{C}$ & $\mathrm{P} 40$ & B pith, $40 \% \mathrm{H}_{3} \mathrm{PO}_{4}, 500^{\circ} \mathrm{C}, 3 \mathrm{~h}$ \\
\hline FS 700 & B fiber, $2 \mathrm{~h}$, steam at $700^{\circ} \mathrm{C}$ & P 50 & $\mathrm{~B}$ pith, $50 \% \mathrm{H}_{3} \mathrm{PO}_{4}, 500^{\circ} \mathrm{C}, 3 \mathrm{~h}$ \\
\hline \multirow[t]{2}{*}{ FS 800} & B fiber, $2 \mathrm{~h}$, steam at $800^{\circ} \mathrm{C}$ & & \\
\hline & & P 50/400 & B pith, $50 \% \mathrm{H}_{3} \mathrm{PO}_{4}, 400^{\circ} \mathrm{C}, 3 \mathrm{~h}$ \\
\hline PS 600 & B pith, $2 \mathrm{~h}$, steam at $600^{\circ} \mathrm{C}$ & P 50/600 & $\mathrm{B}$ pith, $50 \% \mathrm{H}_{3} \mathrm{PO}_{4}, 600^{\circ} \mathrm{C}, 3 \mathrm{~h}$ \\
\hline PS 700 & B pith, $2 \mathrm{~h}$, steam at $700^{\circ} \mathrm{C}$ & & \\
\hline \multirow[t]{2}{*}{ PS 800} & B pith, $2 \mathrm{~h}$, steam at $800^{\circ} \mathrm{C}$ & $\mathrm{P} 50 / 1$ & B pith, $50 \% \mathrm{H}_{3} \mathrm{PO}_{4}, 500^{\circ} \mathrm{C}, 1 \mathrm{~h}$ \\
\hline & & $\mathrm{P} 50 / 2$ & $\mathrm{~B}$ pith, $50 \% \mathrm{H}_{3} \mathrm{PO}_{4}, 500^{\circ} \mathrm{C}, 2 \mathrm{~h}$ \\
\hline B 30 & Whole $\mathrm{B}, 30 \% \mathrm{H}_{3} \mathrm{PO}_{4}, 500^{\circ} \mathrm{C}, 3 \mathrm{~h}$ & P 50/170 & B pith, $50 \% \mathrm{H}_{3} \mathrm{PO}_{4}, 170 / 500^{\circ} \mathrm{C}, 3 \mathrm{~h}$ \\
\hline B 40 & Whole $\mathrm{B}, 40 \% \mathrm{H}_{3} \mathrm{PO}_{4}, 500^{\circ} \mathrm{C}, 3 \mathrm{~h}$ & & \\
\hline \multirow[t]{2}{*}{ B 50} & Whole $\mathrm{B}, 50 \% \mathrm{H}_{3} \mathrm{PO}_{4}, 500^{\circ} \mathrm{C}, 3 \mathrm{~h}$ & B 50A & Whole $\mathrm{B}, 50 \% \mathrm{H}_{3} \mathrm{PO}_{4}, 500^{\circ} \mathrm{C}$, air \\
\hline & & F 50A & B fiber, $50 \% \mathrm{H}_{3} \mathrm{PO}_{4}, 500^{\circ} \mathrm{C}$, air \\
\hline F 30 & B fiber, $30 \% \mathrm{H}_{3} \mathrm{PO}_{4}, 500^{\circ} \mathrm{C}, 3 \mathrm{~h}$ & P 50A & B pith, $50 \% \mathrm{H}_{3} \mathrm{PO}_{4}, 500^{\circ} \mathrm{C}$, air \\
\hline
\end{tabular}

Table 1. Description of activation conditions for investigated activated carbons 
Table 2. X-ray diffraction patterns of activated carbons prepared under the steam pyrolysis scheme

\begin{tabular}{|c|c|c|c|c|}
\hline \multirow[b]{2}{*}{ Sample } & \multicolumn{2}{|c|}{1} & \multicolumn{2}{|c|}{2} \\
\hline & $\begin{array}{l}\mathrm{d} \\
\AA \\
\AA\end{array}$ & $\begin{array}{c}\text { I } \\
\%\end{array}$ & $\begin{array}{l}\mathrm{d} \\
\AA \\
\AA\end{array}$ & $\begin{array}{l}\text { I } \\
\%\end{array}$ \\
\hline BS 600 & 3.87 & 75 & 2.03 & 43 \\
\hline BS 700 & 3.87 & 88 & 2.04 & 36 \\
\hline BS 800 & 3.87 & 100 & 2.04 & 30 \\
\hline FS 600 & 3.93 & 78 & 2.04 & 18 \\
\hline FS 700 & 3.87 & 60 & 2.04 & 30 \\
\hline FS 800 & 3.87 & 50 & 2.04 & 30 \\
\hline PS 600 & 3.87 & 48 & 2.03 & 25 \\
\hline PS 700 & 3.87 & 62 & 2.03 & 25 \\
\hline PS 800 & 3.87 & 100 & 2.03 & 26 \\
\hline
\end{tabular}

Table 3. X-ray diffraction patterns of activated carbons prepared by the standard $\mathrm{H}_{3} \mathrm{PO}_{4}$-procedure

\begin{tabular}{ccccccccc}
\hline & \multicolumn{2}{c}{1} & \multicolumn{2}{c}{2} & \multicolumn{3}{c}{3} & \multicolumn{2}{c}{4} \\
\cline { 2 - 10 } Sample & $\mathrm{d}$ & $\mathrm{I}$ & $\mathrm{d}$ & $\mathrm{I}$ & $\mathrm{d}$ & $\mathrm{I}$ & $\mathrm{d}$ & $\mathrm{I}$ \\
& $\AA$ & $\%$ & $\AA$ & $\%$ & $\AA$ & $\%$ & $\AA$ & $\%$ \\
\hline B 30 & 3.87 & 100 & 3.371 & 73 & 3.07 & 42 & 2.03 & 37 \\
B 40 & 3.76 & 90 & 3.371 & 100 & 3.07 & 77 & 2.07 & 33 \\
B 50 & 3.86 & 100 & 3.401 & 78 & 3.07 & 62 & 2.03 & 26 \\
& & & & & & & & \\
F 30 & 3.84 & 98 & 3.400 & 100 & 3.07 & 65 & 2.03 & 46 \\
F 40 & 3.77 & 99 & 3.39 & 100 & 3.08 & 72 & 2.03 & 49 \\
F 50 & 3.87 & 94 & 3.40 & 100 & 3.04 & 91 & 2.02 & 44 \\
& & & & & & & & \\
P 30 & 3.87 & 100 & 3.43 & 75 & 3.07 & 31 & 2.03 & 18 \\
P 40 & 3.75 & 100 & 3.37 & 84 & 3.07 & 51 & 2.03 & 35 \\
P 50 & 3.76 & 96 & 3.38 & 100 & 3.07 & 72 & 2.03 & 33 \\
\hline
\end{tabular}

where $\beta$ represents full-width at half maximum, fwhm [in radians $(\mathrm{R})$ of $\theta, \mathrm{R}=0.01745 \theta^{\circ}$ ], and $\mathrm{n}$ is the number of graphene sheets. The peak positions were measured and Bragg's law was applied and the d spacing were calculated, in the output data, as shown in Tables 2, 3, 4. Representative diffraction profiles are given in Fig. 1 However, the calculated Lc and La values are not exactly equal to the stacking height and lateral size of the crystallites because these equations are, in fact, actually derived for highly graphitized carbons and are not suitable for turbostratic (fully disordered) carbons. Therefore, these can be used as convenient relative estimates of actual stacking height and lateral size of the crystallites [29]. The actual crystallite sizes, therefore, are likely to be slightly greater than the calculated values.

\section{Results and Discussion}

The diffraction profiles exhibit two prominent broad bands centered around $2 \theta=23$ and $43^{\circ}$, which are currently
Table 4. X-ray diffraction patterns of activated carbons prepared under modified $\mathrm{H}_{3} \mathrm{PO}_{4}$-procedures

\begin{tabular}{lcccccccc}
\hline & \multicolumn{9}{c}{1} & \multicolumn{3}{c}{2} & \multicolumn{3}{c}{3} & \multicolumn{2}{c}{4} \\
\cline { 2 - 9 } Sample & $\mathrm{d}$ & $\mathrm{I}$ & $\mathrm{d}$ & $\mathrm{I}$ & $\mathrm{d}$ & $\mathrm{I}$ & $\mathrm{d}$ & $\mathrm{I}$ \\
& $\AA$ & $\%$ & $\AA$ & $\%$ & $\AA$ & $\%$ & $\AA$ & $\%$ \\
\hline P 50/1h & 3.87 & 87 & 3.41 & 97 & 3.03 & 100 & 2.12 & 42 \\
P 50/2h & 3.72 & 100 & 3.41 & 94 & 3.02 & 92 & 2.11 & 46 \\
P 50/3h & 3.76 & 96 & 3.38 & 100 & 3.07 & 72 & 2.03 & 33 \\
& & & & & & & & \\
P 50/400 & 3.76 & 15 & 3.40 & 30 & 3.01 & 100 & 2.10 & 24 \\
P 50/500 & 3.76 & 96 & 3.38 & 100 & 3.07 & 72 & 2.03 & 33 \\
P 50/600 & 3.74 & 100 & 3.39 & 80 & 3.04 & 60 & 2.04 & 36 \\
P 50/170 & 3.86 & 100 & 3.41 & 82 & 3.06 & 63 & 2.03 & 27 \\
& & & & & & & & \\
B 50A & 3.89 & 100 & 3.43 & 76 & 3.07 & 39 & 2.03 & 23 \\
F 50A & 3.86 & 88 & 3.42 & 71 & 3.07 & 48 & 2.04 & 31 \\
P 50A & 3.89 & 100 & 3.42 & 20 & 3.07 & 19 & 2.03 & 14 \\
\hline
\end{tabular}

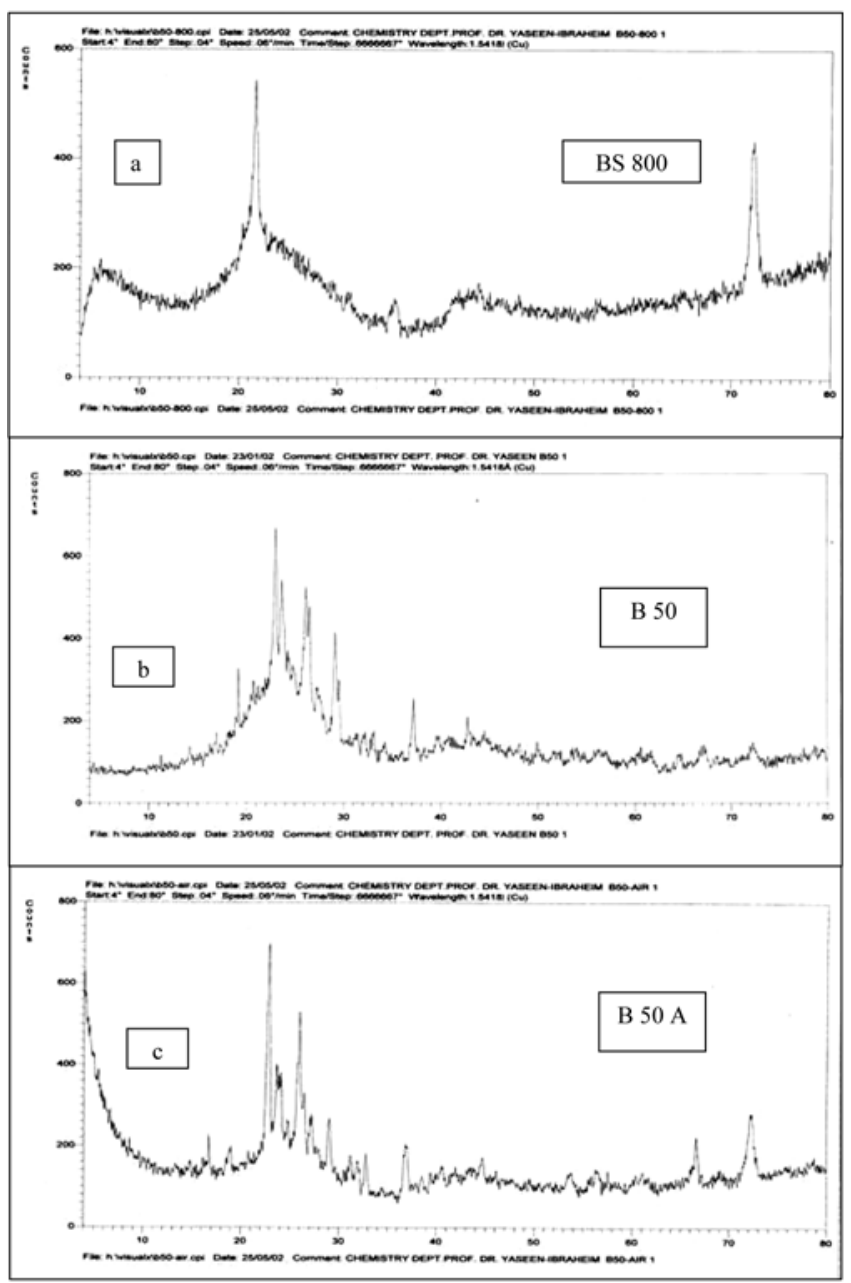

Fig. 1. XRD patterns of representative ACs derived from whole bagasse (a-c) by (a) steam-pyrolysis at $800^{\circ} \mathrm{C}$, (b) standard $\mathrm{H}_{3} \mathrm{PO}_{4} 50 \%$ (c) and carbon obtained under flowing air. 
considered mentioned as associated with diffraction of the 002 and 100/101 planes, respectively. These denote the interlayer spacing Lc and microcrystallite diameter La [19], or alternatively the stacking height Lc, and the lateral size of crystallites La [10]. It should be mentioned that an anonymous (unidentified) line appears in most XRD-patterns at $2 \theta=$ $72^{\circ}$, which is strong and sharp.

\subsection{X-ray diffraction profiles of steam-activated carbons}

These profiles appear simple and exhibit only two broad diffraction bands at the general typical graphitic structure at $2 \theta=23$ and $43^{\circ}$, associated with the crystallite height and width. Raising the pyrolysis temperature, from 600 to 800 ${ }^{\circ} \mathrm{C}$, is accompanied by a general and gradual change shown by an increase in sharpness of the $23^{\circ}$-peak. Consequently, an increase in the pseudocrystallite height (Lc) and a small decrease in the lateral crystallite dimension $(\mathrm{La})$, is observed. This means ordering and building of the so-called aromatic sheets as $\mathrm{n}=\mathrm{Lc} / \mathrm{d}_{0002}$ increase from 4 up to 15 , with activation temperature [10]. The interlayer spacings $(d=3.87-3.93$ $\AA$ ) are very similar to several reported data $[10,14]$, and are, meanwhile, higher than the typical graphitic dimensions of $3.35 \AA$ [10]. This observation indicate that obtained carbons are composed of turbostratic (fully disordered) structures. The reasons of this disorder are the presence of local stacking faults, random shifts between adjacent layers, varying interspacing values, unorganized carbons that are not a part of layer structure, and strain in the layers [30].

In the natural lignocellulosic materials different chemical structures are prevailing: these are the linear polymeric cellulose $(\mathrm{Cel})$, side-chained hemi cellulose (Hem) and the aromatic methylated structures of lignin (Li). These are interconnected and interaconnected with linkages of different types forming complex fiber matrix composite material in which the fiber framework consists of crystalline microfibrils of $2-5 \mathrm{~nm}$ diameter. The matrix between the microfibrils is composed mostly of hemicellulose, and lignin provides the strengthening material that solidifies the surrounding cell wall. The microfibrils in the cell walls are formed from cellulose chains that are aligned and held together by hydrogen bonding between the hydroxyl groups on the repeating glucose units. Groups of microfibrils are connected by amorphous cellulose (about 10-20\% of the total cellulose) and hemicelluose, and the array is surrounded by lignin and some hemicelluose [31].

Steam-activation is accompanied by dehydration and gradual dehydrogenation, with breakdown and destruction of the 3-dimensional linkages between the different chemical components ( $\mathrm{Cel}, \mathrm{Hem}, \mathrm{Li})$ to form the skeleton of the fully disorganized graphene sheets. This process preserves ,more or less, the structural relationships between the precursor and the final char product. Raising the temperature promotes the degree of "pseudo" crystallinity, although it is very far from the crystallinity orientation of graphite. Such process actually needs much higher temperatures $\left(1000^{\circ} \mathrm{C}\right.$ and higher) [10]. This explains the very broad and diffuse profiles observed in most XRD-patterns in this case.

\section{2. $\mathrm{X}$-ray diffraction profiles of the standard, $\mathrm{H}_{3} \mathrm{PO}_{4}$-acti- vated carbons}

In this case, diffraction within the range $2 \theta=22-30^{\circ}$, show more developed and separated peaks with maxima at $2 \theta=$ 23, 26 and $29^{\circ}$. This observation may be proposed as to indicate fragmented developed crystallites (as partially organized structures) as the half maximum intensity $(\beta)$ decreases. The second diffraction profiles in the range around $2 \theta=43^{\circ}$, are diffuse and broad with weaker intensity. This indicates that the intragraphitic layers are less developed [21], and that the lateral size of graphene layers did not change significantly under the pyrolysis conditions employed under varying activant concentrations. Variations due to type of precursor (whole bagasse, fiber, or pith) are insignificant. Some diffraction peaks are observed in the low range of $2 \theta=14$ $22^{\circ}$, which disappear upon increased acid concentration $\%$ $\mathrm{H}_{3} \mathrm{PO}_{4}$, duration or temperature. These were attributed to residual cellulose crystallites [32,33], and observed in some other patterns of ACs derived from agricultural products [23, 34]. This means that the attack of $\mathrm{H}_{3} \mathrm{PO}_{4}$ on the lignocellulosic material does not lead to complete destruction in the primary stages, of the constituent cellulose crystallites. It rather degrades it into smaller fragmented entities retaining their parent crystallite form but with different sizes that might explain the diversely observed sharp peaks appearing with this range of $\theta=14-22^{\circ}$, which strongly supports the mechanism of activation postulated earlier [28, 31].

In comparison to the previous $\mathrm{S}$-series of carbons, the Pcarbons exhibit more rich diffraction profiles (Fig. 1), although with diffraction bands within the same angular ranges $(2 \theta=$ $22-30$ and $43-48^{\circ}$ ) in addition to the lower angular range $2 \theta$ $16-22^{\circ}$. But instead of the above described broad and diffuse bands, several well-developed peak maxima are observed at $2 \theta=23,26$ and $29^{\circ}$, corresponding to mean $\mathrm{d}_{002}$ spacing of $3.85,3.39$ and $3.07 \AA$, respectively. They show also strong intensities with relative values of $70-100 \%$, where the range pertains to the first lines. The high angular peaks $\left(43-45^{\circ}\right)$ are more diffuse and broad with much lower diffraction relative intensities $\left(\mathrm{I} / \mathrm{I}_{0}=30-50 \%\right)$. Calculation of the Lc and $\mathrm{La}$ values at the angular values of 23 and $43^{\circ}$, respectively, showed that the apparent crystallite heights (Lc) ranged between 40 and $70 \AA$, and lateral dimensions (La) of 25-40 $\AA$. It seems that the graphene sheets are formed of stacks of around 10-20 layers which are much higher than in case of the steam-activated carbons.

It has been postulated that in chemical activation with $\mathrm{H}_{3} \mathrm{PO}_{4}$ acid, that the activant drastically attacks the parent lignocellulosic plant structure. This process is speculated to 
affect essentially the breadth of the linear cellulose and lignin entities due to cleavage of the ether linkages leading to smaller molecular entities [28]. The original long chain polymeric structures are less affected, where lignin was assumed to be partially dissolved in the strongly acidic medium, but the acid-impregnated and pyrolyzed mass preserves the pseudo-cellulosic structure (in smaller fragments), the effect of $\mathrm{H}_{3} \mathrm{PO}_{4}$ extends also to the formation of new polymeric structures, which might explain the unusual sharp diffraction bands at $\mathrm{d}_{002}=3.39$ and $3.07 \AA$, in addition to the $3.85 \AA$ spacing. This diffraction patterns would be associated with the residual disrupted cellulose, distorted graphene layers and the new polymeric layers (probably with phosphate linkages). Such explanation is evidently based on, and attributed to, the suggested mechanism of chemical activation with phosphoric acid [28, 31], which leads to the appearance of different d-spacings (or different interlayer distances) with three or more values.

\subsection{X-ray diffraction profiles of carbons obtained under modified $\mathrm{H}_{3} \mathrm{PO}_{4}$-activation conditions}

From the above described XRD profiles, it appears that the two variables: the precursor type and impregnant concentration inflicts insignificant structural impacts. Here, three more factors were tried to investigate the effect of HTT, soaking time, and flowing air during pyrolysis, on the diffraction patterns. For this purpose, only one precursor, bagasse pith at $50 \% \mathrm{H}_{3} \mathrm{PO}_{4}$, was subjected to variations in HTT and duration of carbonization, the former is limited to $400-600^{\circ} \mathrm{C}$ range which is the currently employed temperature of treatment $[28,31]$. The action of the three factors (acid concentration, HTT and soaking time) act co-operatively in the transformation of the parent lingocellulosic material to the final "pseudo-graphitic structure" with its repeating units composed of graphene layers, or sheets, as completely dehydrogenated aromatic entities with definite interlayer spacing and well-developed stackings. In the present case, of chemical activation with $\mathrm{H}_{3} \mathrm{PO}_{4}$ at moderate temperatures, the process of complete fragmentation and structural breakdown (with gasification into $\mathrm{H}_{2} \mathrm{O}, \mathrm{CO}_{2}$ and $\mathrm{CO}$ ) is considerably postponed. The biopolymer complicated fibrous structure is mildly or slowly affected to transform into the graphene structures. This explains the high carbon yield in this case $(35-45 \%)$ as compared to the low values observed under the steam-activation scheme (12-17\%).

Intermediate dehydration at $170^{\circ} \mathrm{C}$, before pyrolysis at $500^{\circ} \mathrm{C}$, leads to insignificant structural changes as compared to treatment without this stage. Pyrolysis at $400^{\circ} \mathrm{C}$ results in diffuse and poor diffraction profiles which indicates that this temperature is not sufficient to produce significant structural changes. The new polymeric structures, formed under action of $\mathrm{H}_{3} \mathrm{PO}_{4}$ in the primary stages, seem to be stable and heat resistant as they show no considerable structural changes upon varying either of HTT and/or soaking time. Flowing air during pyrolysis at $500^{\circ} \mathrm{C}$, seems to be the most effective parameter that leads to some observed XRD changes. The presence of flowing air apparently promotes development of the basic structure with regular stacks in the $\mathrm{C}$-axis with d002 spacing of $3.88 \AA$, accompanied by breakdown of the other structures observed at $d$ values of 3.39 , and $3.07 \AA$. Their intensity decreases considerably from the corresponding standard $\mathrm{H}_{3} \mathrm{PO}_{4}$-activation (Tables $3 \& 4$ ). The diffraction broad band observed at $2 \theta=43^{\circ}$, corresponding to the lateral dimensional parameter of the a-planes, appear to be missing or flattened with much lower intensity. Such observation would predict intensive structural degradation and destruction into minute fractions under action of flowing air in the $\mathrm{H}_{3} \mathrm{PO}_{4}$-impregnated biomass. Generally, the diffraction patterns occupy their same position, but with modified intensities and relationships.

\section{References}

[1] Warren, B. E. Phys. Rev. 1934, 2, 551.

[2] Warren, B. E. Phys. Rev. 1941, 59, 693.

[3] Brindley, G. W.; Mering, J. Acta. Crystallogr. 1951, 4, 441.

[4] Hirsch, P. B. Proc. Roy. Soc. Ser A. 1954, 226, 143.

[5] Diamond, R. Acta Crystallogr. 1957, 10, 359.

[6] Diamond, R. Acta Crystallogr. 1958, 11, 129.

[7] Short, M. A.; Walker, P. L. Jr. Carbon. 1963, 1, 3.

[8] Bacon, R. "Chemistry and physics of carbon", ed. Walker, P. L., Jr., Thrower, P. A., Marcel Dekker,. 1973, 1-95, New York.

[9] Oberlin, A. Carbon 1984, 22, 521.

[10] Sakintuna, B.; Yurum, Y. Energy \& Fuels 2004, 18, 883.

[11] Byrne, J. F.; Marsh, H. "Porosity in Carbons: Characterization and Applications", ed. J. W. Patrick, Edward Arnold Inc., London, 1995, chap. 1.

[12] Walker, P. L. Jr. Carbon. 1986, 24, 379.

[13] Haghseresht, F.; Fu, G. Q.; Whittaker, A. K. Carbon 1999, 37, 1491.

[14] Yoshizawa, N.; Maruyama, K.; Yamada, Y.; ZielinskaBlajet, M. Fuel 2000, 79, 1461.

[15] Kumar, M.; Gupta, R. C.; Sharma, T. J. Mater. Sci. 1993, 28,805 .

[16] Fryer, J. R. Carbon 1981, 19, 431.

[17] Mc Enaney, B. Carbon 1988, 26, 267.

[18] Huttepain, M.; Oberlin A. Carbon 1990, 28, 103.

[19] Suarez-Garica, F.; Martinez-Alonso, A.; Tascon, J. M. D. J. Anal. Appl. Pyr. 2003, 63, 283.

[20] Yoshizawa, N.; Maruyama, K.; Yamada, Y.; Ishikawa, E.; Kobayashi, M.; Toda, Y.; Shiraishi, M. Fuel 2002, 81, 1717.

[21] Ishii, C.; Kaneko, K. Prog. Org. Coat. 1997, 31, 147.

[22] Pastor-Villegas, J.; Gomez-Serrano, V.; Duran-Valle, C. J.; 
Highes-Rolando, F. J. Anal. Appl. Pyr. 1999, 50, 1.

[23] Tsoncheva, T.; Vankova, S.; Mehandjiev, D. Fuel. 2003, 82,755 .

[24] Tsoncheva, T.; Nickolov, R.; Vankova, S.; Mehandjiev, D. Can. J. Chem. 2003, 81, 1096.

[25] Alaya, M. N.; Girgis, B. S.; Mourad, W. E. J. Por. Mat. 2000, 7, 509.

[26] Girgis, B. S.; Khalil, L. B.; Tawfik, T. A. M. J. Por. Mat. 2002, 9, 105.

[27] Girgis, B. S.; Khalil, L. B.; Tawfik, T. A. M. J. Chem. Tech. Biotech. 1994, 61, 87.
[28] Girgis, B. S.; El-Hendawy, A. N. A. Microp. Mesop. Mat. 2002, 52, 105.

[29] Gurudatt, K.; Tripathi, V. S. Carbon 1998, 36, 1371.

[30] Babu, V. S.; Sechra, M. S. Carbon 1996, 34, 1259.

[31] Jagtoyen, M.; Derbyshire, F. Carbon 1998, 36(7/8), 1085.

[32] Yun, C. H.; Park, Y. H.; Park, C. R. Carbon 2001, 39, 559.

[33] Yun, C. H.; Park, Y. H.; Oh, G. H.; Park, C. R. Carbon 2002, 41, 2009.

[34] Hong, Y.; Proctor, A.; Schultz, J. JAOCS. 2000, 77(7), 785. 